\title{
Risk perception and evacuation decisions of Florida tourists under hurricane threats: a stated preference analysis
}

\author{
Corene Matyas • Sivaramakrishnan Srinivasan • Ignatius Cahyanto • \\ Brijesh Thapa $\cdot$ Lori Pennington-Gray $\cdot$ Jorge Villegas
}

Received: 3 December 2010/ Accepted: 23 March 2011/Published online: 13 April 2011

(C) Springer Science+Business Media B.V. 2011

\begin{abstract}
Though most hurricane evacuation studies have focused on residents, tourists are also a vulnerable population. To assess their perceptions of risk and evacuation likelihood under different hurricane conditions, we surveyed 448 tourists visiting central Florida. Respondents viewed four maps emulating track forecast cones produced by the National Hurricane Center and text information featuring variations of storm intensity, coast of landfall, centerline position relative to the survey site, time until landfall, and event duration. We performed chi-square tests to determine which hurricane conditions, and aspects of tourists such as their demographics and previous hurricane experience, most likely influenced their ratings of risk and evacuation likelihood for respondents located on Pinellas County beaches or inland near Orlando, FL. Highly rated scenarios featured a Category 4 hurricane making landfall along the Gulf Coast with the centerline passing over the sampling site. Overall, tourists that indicated the highest risk and evacuation ratings were not previously affected by a hurricane, had a trip duration of less than 6 days, and had checked for the possibility of a hurricane strike before departure. However, results for other tourist attributes differed between tourists in coastal and inland locations. We found that although somewhat knowledgeable about hurricanes, tourists misinterpreted the track
\end{abstract}

\author{
C. Matyas $(\bowtie)$ \\ Department of Geography, University of Florida, 3141 Turlington Hall Box 117315, \\ Gainesville, FL 32611, USA \\ e-mail: matyas@ufl.edu

\section{S. Srinivasan} \\ Department of Civil and Coastal Engineering, University of Florida, Gainesville, FL, USA \\ I. Cahyanto · B. Thapa · L. Pennington-Gray \\ Tourism Crisis Management Institute, Eric Friedheim Tourism Institute, \\ University of Florida, Gainesville, FL, USA \\ I. Cahyanto · B. Thapa $\cdot$ L. Pennington-Gray \\ Department of Tourism, Recreation, and Sport Management, University of Florida, \\ Gainesville, FL, USA \\ J. Villegas \\ Department of Business Administration, University of Illinois at Springfield, Springfield, IL, USA
}


forecast cone and hurricane conditions, which led to a lower perception of risk and subsequent likelihood to evacuate. Tourists, particularly those from outside of Florida, need to be better educated about the risks they face from hurricanes that make landfall.

Keywords Hurricanes $\cdot$ Tourists $\cdot$ Evacuation $\cdot$ Risk perception $\cdot$ Florida

\section{Introduction}

Hurricanes affect Florida more than any other US state (Elsner et al. 2004). While storm surge and damaging winds are major concerns along the coastline, people located inland are also vulnerable to hurricane force winds, tornadoes, and flooding from heavy rainfall (Rappaport 2000). Given that hurricanes can cause widespread destruction, efficient evacuation strategies are critical for saving lives. Many recent studies have examined evacuation behaviors of residents in response to hurricanes (e.g., Arlikatti et al. 2006; Cutter and Finch 2008; Kang et al. 2007; Kusenbach et al. 2010; Senkbeil et al. 2010; Smith and McCarty 2009; Zhang et al. 2007). These studies have shown that hurricanerelated conditions such as intensity and projected track and personal attributes (i.e., experiencing false alarms, owning pets, income, and age) affect the perceptions of risk and evacuation decisions of residents.

However, especially in the context of Florida, it is important to specifically address the evacuation behavior of tourists. According to Visit Florida (2010), the State receives approximately 80.9 million $(88.1 \%$ are domestic) visitors annually, many of whom arrive during the hurricane season that spans June 1-November 30. Tourists are a vulnerable population for several reasons (Phillips and Morrow 2007) including the fact that they may lack knowledge about the risks presented by hurricanes. Also, they are typically in unfamiliar surroundings and are without the normal support systems of their home community (Burby and Wagner 1996; World Tourism Organization 1998). Yet, the few significant contributions on the evacuation of tourists during hurricanes have been published largely by one author (Drabek 1991, 1993, 1994, 1996) whose work principally focused on evacuation strategies and policies from a supply perspective. Few studies have examined the demand perspective (i.e., the tourists' preferences and intentions), and to our knowledge, no empirical studies of tourists perceptions and evacuation preferences under hurricane threats have been published and/or available.

This study is a first toward a comprehensive understanding of the risk perception and evacuation decisions of tourists in response to hurricanes that make landfall. We examined tourists who visited central Florida to determine how knowledgeable they were about hurricanes, how many had previous experience with hurricanes, and what factors influenced their perceptions of risk and evacuation plans when a hurricane was expected to affect the area. Our three main hypotheses were as follows:

(1) Location: Tourists on the coast will perceive a higher risk and be more likely to evacuate than tourists located inland.

(2) Hurricane characteristics: The information that a tourist receives about the hurricane characteristics, such as storm intensity, the track of the storm, the time to landfall, and landfall location strongly influences their perceptions of risk and evacuation decisions. 


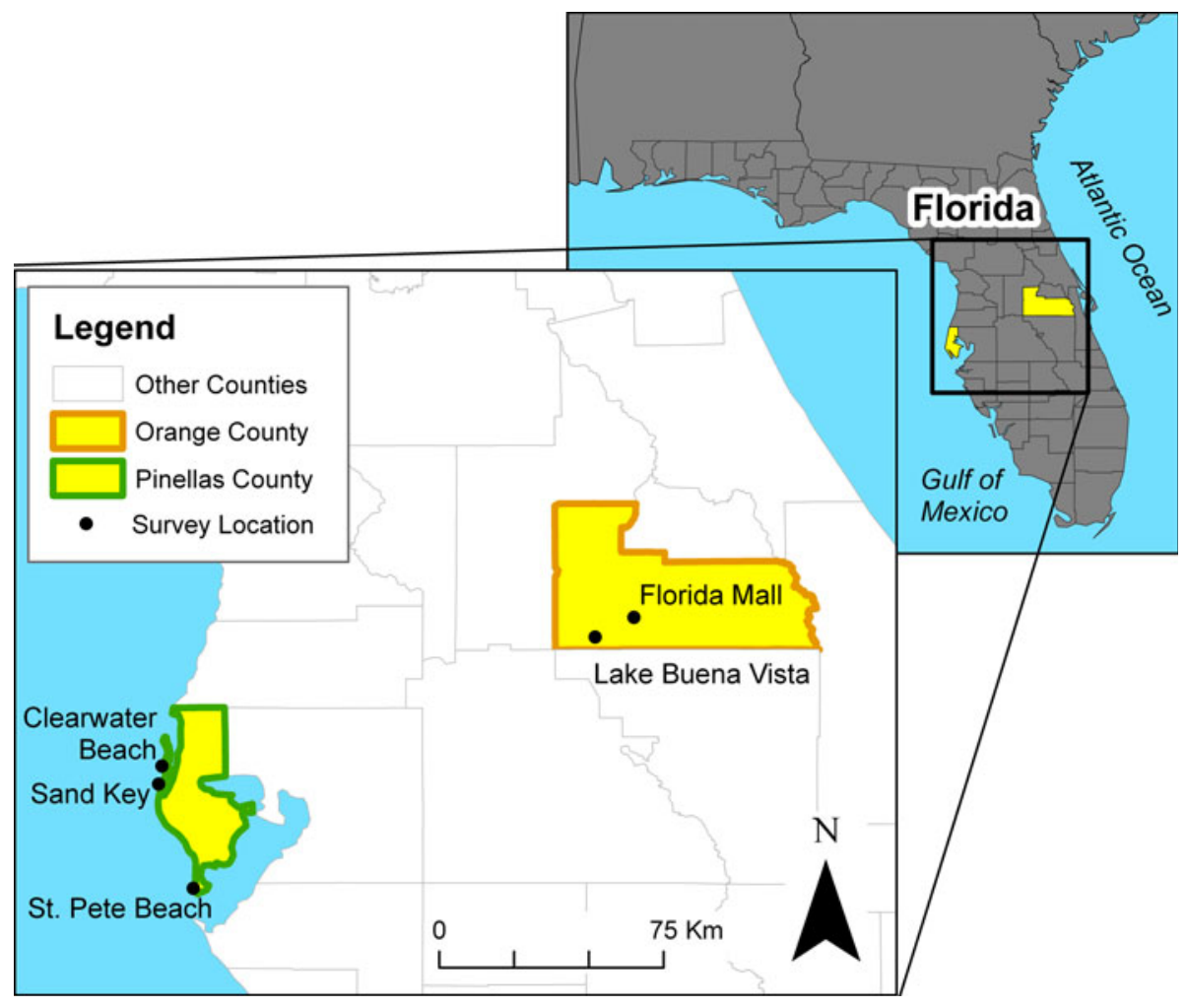

Fig. 1 Survey site locations in Pinellas and Orange Counties, Florida

(3) Tourist attributes: The attributes of the tourists, such as their knowledge and experience about hurricanes, mode of transportation, and age strongly influence their perceptions of risk and evacuation decisions.

To empirically test the hypotheses, stated preference (SP) surveys were administered to 448 tourists that had visited the Orlando area (inland) and the Clearwater-St Petersburg region (coastal) in Pinellas County, Florida (Fig. 1). Each tourist viewed four different scenarios that depicted a hurricane forecast to make landfall in Florida and affect their current location. For each scenario, they indicated the level of risk involved with remaining in their present location and the likelihood to evacuate. We employed non-parametric chisquare tests (Wilks 1995) to determine that hurricane conditions and tourist attributes produced statistically significant higher or lower ratings of risk and the likelihood to evacuate than expected.

\section{Relevant literature}

The communication of risk for a specific event starts from an original source that transmits information either directly to the ultimate receiver or through intermediaries such as media (Burnside et al. 2007; Lindell and Perry 2004; Lindell and Prater 2007). In the USA, the National Hurricane Center (NHC) issues statements about the potential for a hurricane to 
affect a certain area (Rappaport et al. 2009; Sheets 1990). The NHC uses a map referred to as the track forecast cone (NHC 2011) to convey the likelihood that a tropical cyclone will pass near a given location. The size of the cone is based upon track forecast errors during the past 5 years, not the size of the storm, and the NHC expects the center of the storm to be located within the cone $60-70 \%$ of the time. As the effects of hurricanes may extend hundreds of kilometers from their center (NHC 2011), people located outside of the cone may still be at risk from the storm. Unfortunately, Broad et al. (2007) found that the "Cone of Uncertainty" as it is referred to by the public is widely misunderstood by Florida residents as they place too much focus on the location of the centerline. Yet, their study concludes that the majority of residents indicate that this graphic plays a major role in their evacuation decisions. Tourists that reside outside of hurricane-prone regions may be even more likely to incorrectly interpret their risk of experiencing hurricane conditions after viewing the track forecast cone. In addition to viewing this map on television or the Internet, tourists may gain information related to the estimated place of landfall and storm track, projected intensity (the speed of the maximum sustained one-minute wind), and time until landfall from sources such as hotel staff or other tourists. Thus, it is important to gauge the reactions of tourists to such maps and to understand the method by which hurricane-related information is sought.

Some researchers have studied the impact of risk perceptions on tourists' decisions according to the type of risk. Examples include natural risks such as an earthquake (Huan et al. 2004), terrorism (Uriely et al. 2007) or exposure to health risks such as SARS (Lau et al. 2004). Other researchers have approached the study of risk by testing the effects on decision making of diverse risks (Floyd et al. 2004; Kozak et al. 2007; Lepp and Gibson 2008; Park and Reisinger 2010; Thapa et al. 2008). Kozak et al. (2007), for instance, found that potential tourists' perceptions of high risk of infectious disease or a terrorist act influence the likelihood to change plans to visit a place for touristic reasons, but this effect was not found for other risks such as natural disasters. Overall, the key finding of the reviewed research suggests that in general higher perceptions of risk lead to reduced intention to visit. However, results of such studies also indicate that individual traits such as gender, education, and country of origin have a large impact on the levels of risk perceptions as well as the relationship between risk and behavioral intention (for a detailed review see Park and Reisinger 2010). Based on the literature, the majority of risk-related studies in tourism focus on pre-travel decisions when potential tourists are evaluating likelihoods of risk and their impact on the selection of destination. However, analyses of tourists' decision-making process in case of events that threaten their health or safety while on vacation are relatively scarce. The purpose of this study is to offer a first step to close this gap by focusing on tourists' decision-making processes after they have been exposed to a message that explains the nature of a crisis or natural disaster.

Most studies have examined the actions of residents during natural disasters, yet evacuation decisions of tourists are formulated under differing circumstances compared to those of residents. Previous research has shown that access to a vehicle is important for evacuation (e.g., Cutter and Smith 2009; Eisenman et al. 1997), but many tourists may fly into the region and/or may rent a vehicle but be unfamiliar with evacuation routes. For example, in Florida, almost an even split of visitors arrive by air versus non-air transport (car, RV, train, bus, or other) (Visit Florida 2010). In a study of international tourists, Sönmez and Graefe (1998) found that perceptions of risk or safety can alter rational decision making as it pertains to travel modes and choices while in a destination. Also, tourists may perceive locations that have been affected by previous natural disasters (i.e., Miami or Key West) as more risky than destinations, which have not been hit by past 
natural disasters. Thus, tourists that visit an inland city such as Orlando, Florida, may perceive the location to be less at risk from a hurricane strike when compared to the coast, and hence, may be less inclined to evacuate given the same scenario as a coastal tourist. Additionally, West and Orr (2007) found that having children and living near the coast were important factors in the evacuation decisions of residents, but gender and race were not. However, the composition of tourist groups may differ from resident populations in terms of their group size, the number of children present, ethnic backgrounds, income, education, and age.

Communicators of hurricane-related information cannot assume that all members of the general public have the requisite prior knowledge to comprehend the information and formulate a plan of action in response to hurricane forecasts in the same manner. This may be especially true in comparison with residents and tourists. Residents of hurricane-prone regions are more likely to understand hurricane-specific information as they are exposed to hurricane-related terminology before and during the hurricane season and more frequently when a hurricane has the potential to strike their area (Daniels and Loggins 2007; Dow and Cutter 2002). Previous experience with hurricanes has been linked to lower evacuation rates of resident populations (Rincon et al. 2001; Kusenbach et al. 2010), yet other researchers have found that those previously involved in hurricane evacuations are more willing to evacuate for future storms (Baker 1991; Riad et al. 1999). Since there has been a paucity of research that has considered tourist responses to hurricanes, it is important to gauge their level of knowledge and experience and to determine how it influences their evacuation decisions.

\section{Survey design}

Data on evacuation decisions (i.e., behavioral action) can be collected through revealed preference (RP) or stated preference (SP) surveys. RP surveys involve eliciting data on actual actions, whereas SP surveys involve eliciting behavioral intentions of respondents under hypothetical scenarios (Hess et al. 2006; Kroes and Sheldon 1988; Wardman 1988). In the context of hurricane evacuations, all studies to date have focused on resident populations and most employed the RP method (e.g., Baker 1991; Smith and McCarty 2009 and studies referenced therein). The few studies employing SP techniques (in the context of resident populations) include Lazo et al. (2010), Whitehead (2003, 2005), Whitehead et al. (2000), and Fu (2004). As tourists represent a transient population, collecting RP data from tourists about actual hurricane experiences may be even more difficult than similar data from residents. Despite the fact that the intentions of tourists revealed in an SP survey may differ from their actions when a hurricane landfall actually occurs, the SP approach is appropriate to examine the intended responses of tourists to hurricane-related scenarios and hence was adopted in this study.

Five survey sites were selected based on the probability of high volumes of tourists (Fig. 1). The Orlando area represented the inland destination, and we collected 304 surveys from two sites: (1) the Florida Mall and (2) Wyndham Bonnet Creek Resort in Lake Buena Vista. We collected 144 surveys from Pinellas County, which were administered at three Gulf of Mexico beaches: (1) Sheraton Sand Key Resort, (2) Clearwater Beach/Pier 60, and (3) St. Pete Beach. The surveys were conducted during July 22-August 9, 2009. No hurricanes were present within the Atlantic Ocean basin during or prior to this period as the first named storm of 2009 formed on August 11. A screening question was employed to identify tourists, which we defined as those that had travelled greater than 50 miles as this 
is the definition utilized by the state of Florida (Florida Statute 125.104). We verified this distance by plotting the location of each zip code supplied by the respondent within ArcGIS and calculating the straight-line distance between the coordinates of the survey location and those of the centroid of the polygon enclosing the zip code. Only one adult filled out the 27-question survey per group.

When completing the 3-page survey, participants first indicated information pertaining to their trip logistics (e.g., frequency of visits, mode of transportation, group composition). The second section assessed knowledge about hurricanes through four true/false questions (Fig. 2). We later determined which respondents answered all four questions correctly, as well as those who indicated that they did not know. The third section assessed hurricane experience and preparedness by asking whether tourists or their family or friends had been affected by a hurricane or typhoon and whether they had checked for the possibility of a hurricane occurring during their visit. They then indicated the sources of information that they were likely to use to learn about hurricanes during their trip (Fig. 2). Finally, demographic information was collected such as gender, age, income, and zip code or country of residence, which were later categorized as residing within Florida but outside of a 50-mile radius of the survey location, outside of Florida but within the USA and outside of the USA. All variables utilized in the analysis are listed with their possible responses in Table 1.

A review of the literature demonstrates that the location of a storm and its intensity are important considerations for residents when making the decision to evacuate; evacuation likelihood increases for stronger storms that hit closer to the respondent's location (Baker 1991; Dow and Cutter 2002; Smith and McCarty 2009). Our study aimed to examine

\begin{tabular}{|c|c|c|c|c|c|}
\hline Statement & Not at all & $\gg$ & & $\gg \gg$ & Very Much \\
\hline (a) I would rather be safe than sorry. & 1 & 2 & 3 & 4 & 5 \\
\hline (b) I like to make well-informed decisions. & 1 & 2 & 3 & 4 & 5 \\
\hline (c) I am generally a happy person. & 1 & 2 & 3 & 4 & 5 \\
\hline (d) I am easily frightened. & 1 & 2 & 3 & 4 & 5 \\
\hline
\end{tabular}

10. Circle whether the following statements are True (T), False (F), or Don't Know (DK) based on your knowledge.

\begin{tabular}{|c|c|c|c|}
\hline (a) The "Hurricane Season" in Florida extends from June 1 to Nov & $\mathrm{T}$ & F & DK \\
\hline (b) It is rare for hurricane-force winds to affect cities that are located inland away from the coast. & $\mathrm{T}$ & $\mathrm{F}$ & DK \\
\hline (c) A Category 1 hurricane has the least intensity among all hurricanes. & $\mathrm{T}$ & F & DK \\
\hline (d) If a "Hurricane Warning" has been issued, it & $\mathrm{T}$ & F & $\mathrm{K}$ \\
\hline
\end{tabular}

11. Have you ever been affected by a hurricane/typhoon while traveling? Yes No

12. If your response to the previous question is "Yes", what did you do? (Check only one) Canceled the rest of the trip and returned home Relocated to another destination Remained at the destination through the hurricane Other please specify $\rightarrow$

13. Has any of your family/friends ever been affected by a hurricane/typhoon? Yes No

14. During a trip, from what sources are you likely to learn about hurricanes? (Check all that apply)

$\begin{array}{ll}- & \begin{array}{l}\text { Hotel staff } \\ \text { Other tourists } \\ \text { Website/Internet } \\ \text { Wewspaper }\end{array} \\ \text { Weather Channel } & \end{array}$

15. Before departing for this trip, did you (or anyone else in your group) check for the possibility of a Hurricane striking your destination location during your stay here?

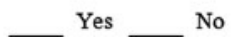

Fig. 2 Portion of the survey asking tourists about their hurricane knowledge, experience, and information sources they are likely to use 
Table 1 Variables acquired through survey responses and their categorical groupings

\begin{tabular}{|c|c|c|}
\hline Name & Description & Possible values \\
\hline Coast & Florida landfall coast & $1=$ Atlantic, $0=$ Gulf \\
\hline Land time & Time to landfall & $1=24 \mathrm{~h}, 0=48 \mathrm{~h}$ \\
\hline Category & S.S. Category at landfall & $1=$ Category $1,0=$ Category 4 \\
\hline Duration & Wind duration & $1=$ Short, $0=$ Long \\
\hline Track & Track passage rel. to site & $1=$ Offset from survey site, $0=$ Over survey site \\
\hline Risk & Perceived level of risk & $0=$ Do not know, $1=$ Not at all $\ldots 5=$ Very much \\
\hline Evacuate & Likelihood of evacuation & $0=$ Do not know, $1=$ Very unlikely $\ldots . .5=$ Very likely \\
\hline F Visit & First visit to destination & $0=$ No, $1=$ Yes \\
\hline N Visit & No. FL visits past 5 years & $1=0-1,2=2-3,3=4-5,4=$ GT 5 \\
\hline N Days & Number of days in trip & $1=0-5,2=6-10,3=11-16,4=$ GT 16 \\
\hline Accom & Accommodations & $\begin{array}{l}1=\text { Hotel, } 2=\text { Camp ground, } 3=\text { Resort, } 4=\text { Friend, } \\
5=\text { Bed/breakfast, } 6=\text { Other }\end{array}$ \\
\hline Group Size & Number of persons in group & $1=1-2,2=3,3=4,4=$ GT 4 \\
\hline Child & Children in group & $0=$ No, $1=$ Yes \\
\hline Mode AP & Plane was used & $0=$ No, $1=$ Yes \\
\hline Mode PT & Public transportation used & $0=$ No, $1=$ Yes \\
\hline Mode PV & Personal vehicle was used & $0=$ No, $1=$ Yes \\
\hline Mode RV & Rental vehicle was used & $0=$ No, $1=$ Yes \\
\hline Q right & All know 1 questions right & $0=$ No, $1=$ Yes \\
\hline Q unknown & $1+$ quest. did not know & $0=$ No, $1=$ Yes \\
\hline Affect P & $\begin{array}{l}\text { Affected by a hurricane } \\
\text { personally }\end{array}$ & $0=$ No, $1=$ Yes \\
\hline Affect F & Friends/Family Affected & $0=$ No, $1=$ Yes \\
\hline Info TV & Information from TV & $0=$ No, $1=$ Yes \\
\hline Info Hot & Information from hotel staff & $0=\mathrm{No}, 1=\mathrm{Yes}$ \\
\hline Info WC & $\begin{array}{l}\text { Information from Weather } \\
\text { Channel }\end{array}$ & $0=$ No, $1=$ Yes \\
\hline Info Web & Information from Internet & $0=$ No, $1=$ Yes \\
\hline Info Tour & Information from other tourists & $0=$ No, $1=$ Yes \\
\hline Info News & Information from newspaper & $0=$ No, $1=$ Yes \\
\hline $\begin{array}{l}\text { Hurricane } \\
\text { Possibility }\end{array}$ & $\begin{array}{l}\text { Checked for the possibility } \\
\text { of a hurricane }\end{array}$ & $0=$ No, $1=$ Yes \\
\hline Gender & Gender & $1=$ Male, $2=$ Female \\
\hline Age & Age in 2009 & $1=18-29,2=30-39,3=40-49,4=50-59,5=60+$ \\
\hline Education & Highest level of education & $1=$ High school, $2=$ Bachelor., $3=$ Masters, $4=$ Other \\
\hline Ethnic & Ethnicity & $\begin{array}{l}1=\text { Caucasian, } 2=\text { African American, } 3=\text { Hispanic } \\
4=\text { Asian, } 5=\text { Pacific Islander, } 6=\text { Native American, } \\
7=\text { Mixed race, } 8=\text { Other }\end{array}$ \\
\hline Income & Household income 2008 & $\begin{array}{l}1=\text { LT } \$ 24 \mathrm{~K}, 2=24-35,3=35-50,4=50-75 \\
5=75-100,6=100-125,7=\mathrm{GT} 125\end{array}$ \\
\hline Reside & Aggregate location & $1=$ Florida, $2=$ USA, $3=$ International \\
\hline
\end{tabular}

whether tourists would respond similarly. With respect to SP, tourists were presented with four different scenarios depicting a hurricane forecast to make landfall over Florida. Each scenario consisted of a map designed to represent an actual track forecast cone issued by 
the NHC with the survey location marked as a star, and corresponding text containing information about the intensity and duration. For example, a Category 4 hurricane projected to make landfall in $24 \mathrm{~h}$ along the Gulf Coast of Florida with the centerline passing directly over Pinellas County survey sites and an expected duration of $18 \mathrm{~h}$ (Fig. 3). All scenarios featured the five sampling sites within the white cone. Each scenario featured a combination of five different conditions, with each condition having two possible variations (Table 2).

To limit survey length, each tourist viewed four total scenarios. The scenarios alternated between the Gulf and Atlantic landfalls so that the respondent was able to visually perceive the differences between the successive scenarios. The condition that differed among the landfalls along the same coast was the survey site's position relative to the centerline of the cone. Variation one showed the centerline passing directly over the survey site, while variation two depicted the survey site within the cone, but offset from the centerline by $50-80 \mathrm{~km}$. Again, to limit survey length, all four scenarios included only one of the two possible variations for the remaining three conditions. These conditions were intensity at landfall (Saffir-Simpson Category 1 or 4 (Simpson and Saffir 1974)), time until landfall (approximately 24 or 48 h), and duration of hurricane-force winds (short or long). A short (long) duration was 3 (12) h for a Category 1 and 6, (18) h for a Category 4 hurricane, which correspond to average sizes and forward velocities of hurricanes found in climatological studies (see Kimball and Mulekar 2004; Matyas 2010). Respondents were asked to rate each scenario on a scale of 1-5 based

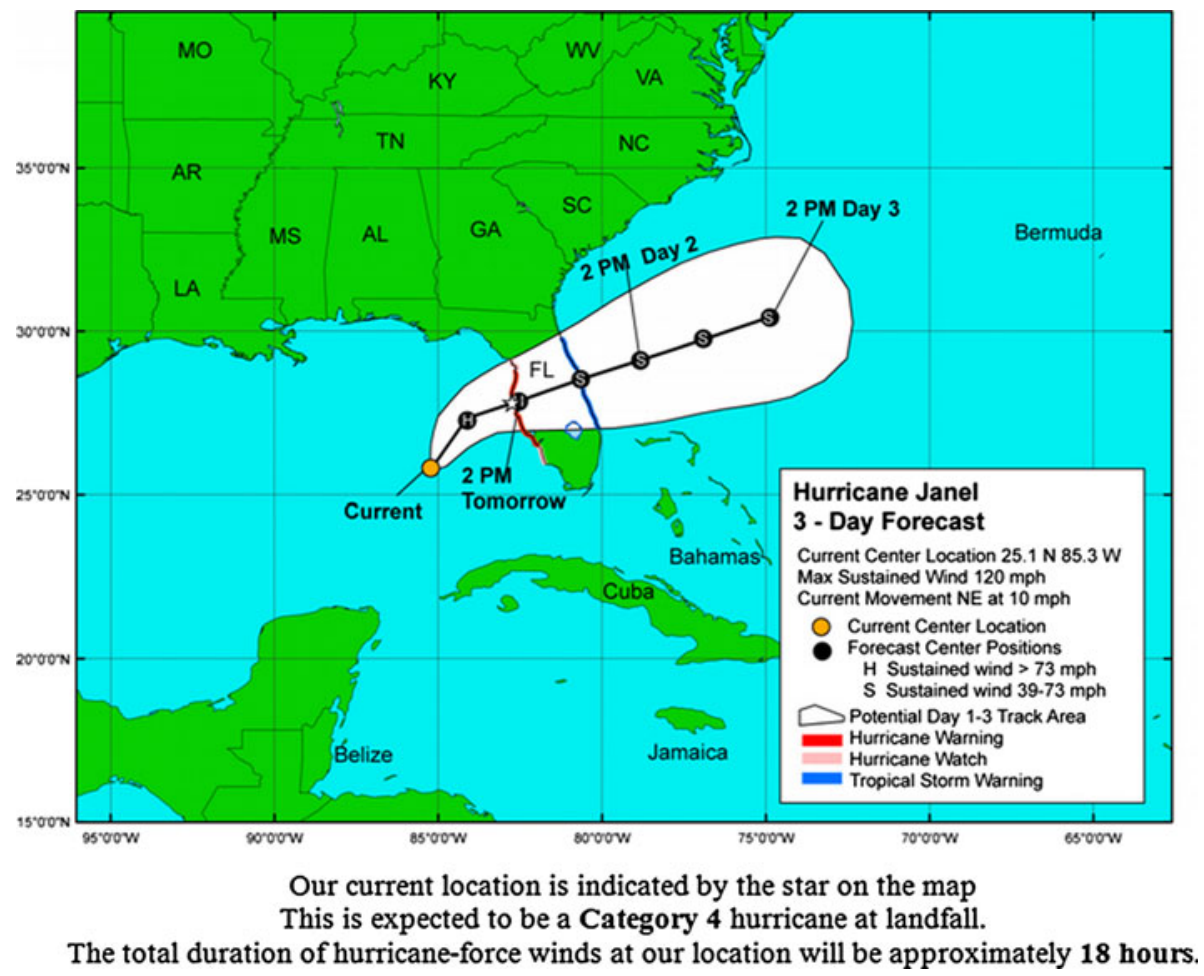

Fig. 3 Scenario number 25 of 32 possible scenarios including graphics designed to closely simulate those issued by the NHC and text to indicate storm intensity and duration. This scenario was hypothesized to yield the highest ratings for risk perception and likelihood to evacuate for tourists surveyed in Pinellas County 
Table 2 Scenarios presented to tourists with two variations each of landfall coast, track, time until landfall, intensity, and duration

\begin{tabular}{|c|c|c|c|c|c|c|c|c|}
\hline $\begin{array}{l}\text { Scenario } \\
\text { number }\end{array}$ & $\begin{array}{l}\text { Landfall } \\
\text { coast }\end{array}$ & $\begin{array}{l}\text { Track } \\
\text { center } \\
\text { line }\end{array}$ & $\begin{array}{l}\text { Time to } \\
\text { landfall } \\
\text { (h) }\end{array}$ & $\begin{array}{l}\text { Saffir-Simpson } \\
\text { category at } \\
\text { landfall }\end{array}$ & $\begin{array}{l}\text { Hurricane } \\
\text { force wind } \\
\text { duration (h) }\end{array}$ & $\begin{array}{l}\text { Number } \\
\text { of ratings }\end{array}$ & $\begin{array}{l}\text { Average } \\
\text { risk }\end{array}$ & $\begin{array}{l}\text { Average } \\
\text { evacuation } \\
\text { likelihood }\end{array}$ \\
\hline 1 & Gulf & Over & 24 & 1 & 3 & 59 & 3.30 & 3.29 \\
\hline 2 & Atlantic & Over & 24 & 1 & 3 & 59 & 3.05 & 3.00 \\
\hline 3 & Gulf & Offset & 24 & 1 & 3 & 61 & 3.10 & 3.05 \\
\hline 4 & Atlantic & Offset & 24 & 1 & 3 & 61 & 2.98 & 3.17 \\
\hline 5 & Gulf & Over & 48 & 1 & 3 & 50 & 3.18 & 3.12 \\
\hline 6 & Atlantic & Over & 48 & 1 & 3 & 50 & 2.92 & 2.90 \\
\hline 7 & Gulf & Offset & 48 & 1 & 3 & 48 & 2.91 & 2.86 \\
\hline 8 & Atlantic & Offset & 48 & 1 & 3 & 49 & 3.08 & 2.88 \\
\hline 9 & Gulf & Over & 24 & 4 & 6 & 51 & 3.57 & $3.56^{*}$ \\
\hline 10 & Atlantic & Over & 24 & 4 & 6 & 48 & 3.09 & 3.13 \\
\hline 11 & Gulf & Offset & 24 & 4 & 6 & 50 & 3.18 & 3.24 \\
\hline 12 & Atlantic & Offset & 24 & 4 & 6 & 50 & 3.00 & 3.04 \\
\hline 13 & Gulf & Over & 48 & 4 & 6 & 47 & $3.73^{*}$ & $3.57 *$ \\
\hline 14 & Atlantic & Over & 48 & 4 & 6 & 48 & 3.35 & 3.28 \\
\hline 15 & Gulf & Offset & 48 & 4 & 6 & 48 & 3.16 & 3.35 \\
\hline 16 & Atlantic & Offset & 48 & 4 & 6 & 49 & 3.22 & 3.08 \\
\hline 17 & Gulf & Over & 24 & 1 & 12 & 42 & 3.29 & 2.85 \\
\hline 18 & Atlantic & Over & 24 & 1 & 12 & 43 & 3.02 & 3.02 \\
\hline 19 & Gulf & Offset & 24 & 1 & 12 & 43 & 3.14 & 3.07 \\
\hline 20 & Atlantic & Offset & 24 & 1 & 12 & 41 & 3.00 & 2.95 \\
\hline 21 & Gulf & Over & 48 & 1 & 12 & 44 & 3.09 & $2.63^{*}$ \\
\hline 22 & Atlantic & Over & 48 & 1 & 12 & 47 & 3.06 & $2.60^{*}$ \\
\hline 23 & Gulf & Offset & 48 & 1 & 12 & 47 & $2.48^{*}$ & 2.85 \\
\hline 24 & Atlantic & Offset & 48 & 1 & 12 & 46 & 2.80 & $2.53^{*}$ \\
\hline 25 & Gulf & Over & 24 & 4 & 18 & 53 & $3.90^{*}$ & 3.19 \\
\hline 26 & Atlantic & Over & 24 & 4 & 18 & 51 & 3.52 & 3.22 \\
\hline 27 & Gulf & Offset & 24 & 4 & 18 & 52 & 3.56 & 3.04 \\
\hline 28 & Atlantic & Offset & 24 & 4 & 18 & 52 & 3.15 & 3.26 \\
\hline 29 & Gulf & Over & 48 & 4 & 18 & 48 & 3.42 & 3.26 \\
\hline 30 & Atlantic & Over & 48 & 4 & 18 & 45 & 3.33 & 3.29 \\
\hline 31 & Gulf & Offset & 48 & 4 & 18 & 43 & 3.14 & 3.00 \\
\hline 32 & Atlantic & Offset & 48 & 4 & 18 & 44 & 3.21 & 3.09 \\
\hline
\end{tabular}

Each tourist viewed one of the groups of four scenarios separated by the blank line. The number of ratings for each scenario and the average ratings for perception of risk and likelihood to evacuate are also presented for each scenario; responses of zero are excluded

* Denotes values 1.5 standard deviations above or below the mean for each column 
You are presented with four messages (see the attached pictures). Each message/picture represents a hypothetical hurricane scenario. After reviewing each scenario carefully, answer the following questions:

Clearlyenter the Scenario ID (number) indicated on the top right corner of the first picture here

17. How risky do you think it would be for you to stay in your current location through this hurricane scenario?

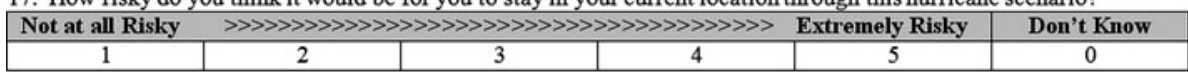

18. How likely are you to evacuate/leave your current location at this time and under this situation?

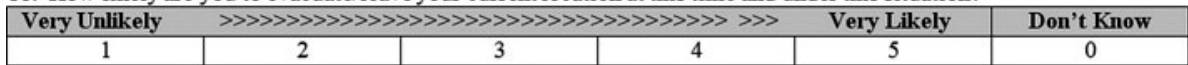

Fig. 4 Portion of the survey asking tourists to rate their responses to each of the four hurricane-related scenarios

upon the level of risk they perceived if they were to remain at their current location and the likelihood that they would evacuate (Fig. 4). Alternatively, they could indicate that they did not know. We expected that the scenarios most likely to have the highest ratings would have a Category 4 intensity, landfall along the closest coast, the centerline passing over the location, $24 \mathrm{~h}$ until landfall, and a long duration.

\section{Profile of respondents}

Most tourists had some knowledge about hurricanes, but their knowledge was incomplete. While $63 \%$ of responses to the four knowledge questions were correct, only $25 \%$ correctly answered all four questions (Table 3). Question 10b (Fig. 2) was most frequently answered incorrectly, and $46 \%$ indicated that they did not know at least one question. Nearly threequarters of the tourists indicated that they had not had any prior experience with hurricanes (Table 3). Of those with past experience, $49 \%$ indicated that they did not evacuate and

Table 3 Percentage of tourists that indicated a response to yes

\begin{tabular}{lc}
\hline Variable & $\%$ Yes \\
\hline F Visit & 34.2 \\
Child & 66.8 \\
Mode AP & 66.7 \\
Mode PT & 2.7 \\
Mode PV & 28.8 \\
Mode RV & 19.1 \\
Q right & 24.5 \\
Q unknown & 45.6 \\
Affect P & 25.8 \\
Affect F & 46.7 \\
Info TV & 84.7 \\
Info Hot & 33.5 \\
Info WC & 44.5 \\
Info Web & 42.7 \\
Info Tour & 12.4 \\
Inf News & 21.8 \\
Hurricane Possibility & 30.3 \\
\hline
\end{tabular}


remained at the destination. A larger portion of the respondents (47\%) indicated that their family or friends had been affected by a hurricane or typhoon (Table 3). Only 30\% of those surveyed had checked for the possibility of a hurricane strike prior to current trip departure (Table 3). Not surprisingly, a larger percentage of those who checked for a hurricane strike answered all four knowledge questions correctly (38\%) compared to those that did not $(22 \%)$.

The demographic variables showed that respondents were almost evenly distributed between males and females (Table 4). Age generally followed a normal distribution with most respondents aged 40-49 (Table 4). Respondents were fairly well educated (33\% holding a Bachelor's degree and 25\% holding a Master's or higher degree) and were relatively affluent with $22 \%$ reporting income of above $\$ 125,000$. Only $9 \%$ noted their income to be less than $\$ 24,000$. With respect to race/ethnicity, Caucasians represented the largest group (Table 4). The majority of tourists were international (48\%), while $38 \%$ were from USA other than Florida (Table 4). According to the results of additional chi-square tests, knowledge and experience exhibit a statistically significant relationship with residence ( $p$ values <0.05). More than $90 \%$ of Florida tourists answered question 10a (Fig. 2) correctly, while approximately $65 \%$ of US non-Florida and international tourists answered correctly. For the other three questions, fewer international respondents answered correctly than expected with more indicating that they did not know the answer as compared to US tourists. Florida respondents recorded the highest number of correct answers. While 77\% of tourists from Florida indicated that a friend or family member had experienced a hurricane or typhoon, only 56\% (34\%) of tourists from the USA (other countries) responded affirmatively to this question.

More than half of the respondents had visited Florida before and most had visited the state multiple times (Table 4). Only 5\% of respondents travelled alone, while $32 \%$ travelled in a group of four (Table 4). One-third of the tourists travelled without children (Table 3), while those traveling with children most often had two children. The majority (67\%) of respondents utilized air transportation during their current trip, with $29 \%$ using a personal vehicle and $19 \%$ a rental (Table 3). Nearly one-third of tourists indicated that their length of stay was between 6 and 10 or 11 and 16 days, and 74\% stayed in a hotel or resort. Local television was selected by $85 \%$ of respondents, followed by the Weather Channel (45\%) and the Internet (43\%) as the information sources likely to be used to learn about hurricanes during a trip (Table 3). These results are somewhat similar to those of Zhang et al. (2007) who interviewed residents after Hurricane Rita (2005) and determined

Table 4 Percent of responses to each tourist attribute category as listed in Table 1

\begin{tabular}{lrrrrrrrr}
\hline Variable & $1(\%)$ & $2(\%)$ & $3(\%)$ & $4(\%)$ & $5(\%)$ & $6(\%)$ & $7(\%)$ & $8(\%)$ \\
\hline N Visit & 31.4 & 32.5 & 16.9 & 19.3 & & & & \\
N Days & 20.9 & 32.1 & 33.0 & 14.0 & & & & \\
Accom & 38.5 & 0.2 & 35.5 & 0.2 & 11.1 & 14.5 & & \\
Group Size & 22.9 & 15.6 & 31.9 & 29.6 & & & & \\
Gender & 50.9 & 49.1 & & & & & & \\
Age & 18.1 & 14.7 & 32.8 & 21.8 & 12.5 & & & \\
Educate & 31.7 & 33.2 & 24.8 & 10.7 & & & & \\
Ethnic & 74.3 & 6.7 & 8.3 & 4.0 & 0.2 & 0.4 & 3.3 & 2.6 \\
Income & 8.7 & 5.4 & 10.0 & 16.9 & 19.5 & 17.4 & 22.1 & \\
Reside & 13.9 & 37.7 & 48.3 & & & & & \\
\hline
\end{tabular}


that hurricane forecasts were most often obtained from broadcast TV and the Weather Channel. However, Zhang et al.'s (2007) study showed radio and personal networks to be much more important than the Internet, while these information sources were not as frequency indicated by tourists in this study.

\section{Risk perception and likelihood of evacuation}

To evaluate which of the 32 scenarios yielded the highest and lowest perceptions of risk and likelihood to evacuate, the average rating for each scenario was calculated. Scenarios with values falling outside of 1.5 standard deviations from the mean were deemed to have exhibited the highest and lowest ratings. Next, we employed chi-square tests to determine which variables produced differences in the response ratings. Each test featured five rows corresponding to the response ratings of $1-5$, and columns corresponding to the variations of each hurricane condition or tourist attribute. The null hypothesis reflected a lack of significant difference between the distribution of response ratings between or among the groups. If the resulting $p$-value was equal to or less than 0.05 , we accepted the alternate hypothesis, indicating that the variable had an effect on the risk perception of the tourists and/or their likelihood to evacuate. It should be noted that the intent was to understand the major associations or relationships, and our methods do not allow the establishment of causal links between any of the factors and the risk perception or evacuation decisions and the various explanatory factors of interest.

The two chi-square tests compared perception of risk and likelihood to evacuate for inland tourists and for coastal tourist, and then two additional tests compared the perception of risk for both regions and the likelihood to evacuate for both regions. For each of the hurricane characteristics and tourist attributes, the ratings of the Orange and Pinellas County tourists were evaluated in separate tests, and risk perception was evaluated separately from evacuation likelihood. Four of the tourist attributes (use of public transportation, accommodation, obtaining information from local television, and ethnicity) as some of the categories produced fewer than five responses to one or more ratings. Thus, four chisquare tests were performed for each of the five hurricane characteristics and each of the remaining 24 tourist attributes (Table 1). Groups with more ratings of 4 and 5 than expected were deemed more likely to evacuate or to perceive a higher level of risk than groups with more ratings of 1 or 2 .

\subsection{Effect of destination location (coastal versus inland)}

The results of the first two chi-square tests indicate that the ratings for risk perception and evacuation likelihood differed between the two survey locations. For evacuation ( $p$-value $<0.0001$ ), more Pinellas County tourists (average rating 3.08) indicated ratings of 4 or 5 than expected; therefore, they were more likely to evacuate than the Orlando tourists (average rating 2.88). This allows us to accept the second part of our first hypothesis. Yet, the test for risk perception $(p$-value $<0.000)$ produced an unexpected result. Although many tourists in Pinellas County rated their level of risk 3-5, many more than expected indicated a rating of 1 or "not at all risky". Thus, the statistical significance of the risk perception test comes from more tourists indicating ratings of 1 and 5 than expected in Pinellas County; whereas we hypothesized that fewer Pinellas County tourists would indicate a rating of 1 than expected. These results indicate that a difference exists between a tourist's perception of risk and their likelihood to evacuate. We also find that even if the 
perceived levels of risk are the same in two locations, the likelihood of evacuation might be different. The results of the chi-square tests support this finding. Statistically significant differences existed in the ratings for risk compared to the likelihood to evacuate ( $p$-value Pinellas County 0.023, Orange County $<0.000$ ).

Hurricane winds experienced in the coastal locations are faster than those located farther inland, and such coastal locations are also at risk from storm surge. Hence, anyone located on a coast that is within the white cone is at risk from a land-falling hurricane. Thus, it is important to explore why one-third of the ratings of 1 and one-half of the ratings of 0 were associated with scenarios that depicted a hurricane making landfall along the Gulf Coast within $80 \mathrm{~km}$ of the survey location. It is possible that these tourists viewed scenarios containing a low intensity, an offset centerline, and/or had $48 \mathrm{~h}$ until landfall and felt that they were not at risk at this time or were unsure of their risk. Yet, recent history has demonstrated that hurricane tracks and intensity can change even within $24 \mathrm{~h}$ of landfall. The errors associated with forecasts of hurricane intensity have not shown significant improvements during the past 15 years (Elsberry et al. 2007), and a hurricane forecast to be at Category 1 intensity could intensify prior to landfall and cause more damage than expected, while a Category 4 hurricane could weaken into a minimal hurricane prior to landfall. In 2004, Hurricane Charley rapidly intensified from Category 2 to Category 4 within several hours of making landfall along Florida's Gulf Coast (Lee and Bell 2007). Even though the projected storm track shifted during this time, the point of landfall had been within the cone but offset from the centerline for $48 \mathrm{~h}$ prior to landfall. Cases such as Charley demonstrate that all of our Gulf Coast scenarios posed some risk to Pinellas County tourists. The presence of risk ratings of 0 and 1 suggests that tourists need to be better educated about the risks associated with remaining at a coastal location when a hurricane is expected to make landfall nearby.

\subsection{Effect of hurricane characteristics}

According to Table 2, scenarios that have the highest ratings depict Category 4 hurricanes making landfall along the Gulf Coast with the centerline passing over the sampling site. Scenarios with the lowest ratings all feature Category 1 hurricanes making landfall within $48 \mathrm{~h}$. Although scenarios 21 and 22 received some of the lower average ratings for likelihood to evacuate, they received a much higher average rating for risk perception. Scenario 17 also received a much higher rating for risk than for likelihood to evacuate, which demonstrated that the perception of risk is likely not the only factor to influence the decision to evacuate. One unexpected result is that the short-duration events received higher ratings than did long-duration events (Table 2). This finding suggests that either a tourist's perception of event duration is not an important factor in their decision-making process, or that duration might not have been processed completely as this information was printed at the bottom of the page and might have been viewed after the perception of risk and decision to evacuate had already been made based on the other hurricane conditions.

An examination of the $p$-values of the chi-square tests (Table 5) allowed us to rank the hurricane conditions in terms of their relative influence on risk perception and the likelihood of evacuation as follows: (1) intensity (2) coast where landfall occurs (3) centerline position, and (4) time until landfall. The duration of hurricane force winds was not included as the null hypothesis was accepted for each test. We found the intensity of the hurricane at the time of landfall was the most important scenario condition as all four of the $p$-values that resulted from the intensity tests were less than 0.05 . Our results are in concert with surveys of coastal residents (Dow and Cutter 2002; Smith and McCarty 2009) that 
Table 5 Results of chi-square tests to determine which hurricane conditions had the greatest influence on the perception of risk and likelihood to evacuate for tourists surveyed in Pinellas and Orange Counties

\begin{tabular}{lllllll}
\hline & $\begin{array}{l}\text { Pinellas } \\
\text { county risk } \\
\text { perception }\end{array}$ & $\begin{array}{l}\text { Pinellas county } \\
\text { likelihood to } \\
\text { evacuate }\end{array}$ & $\begin{array}{l}\text { Variation } \\
\text { with higher } \\
\text { ratings }\end{array}$ & $\begin{array}{l}\text { Orange } \\
\text { county risk } \\
\text { perception }\end{array}$ & $\begin{array}{l}\text { Orange county } \\
\text { likelihood to } \\
\text { evacuate }\end{array}$ & $\begin{array}{l}\text { Variation } \\
\text { with higher } \\
\text { ratings }\end{array}$ \\
\hline Intensity & $\mathbf{0 . 0 1 0}$ & $\mathbf{0 . 0 0 0}$ & Cat. 4 & $\mathbf{0 . 0 3 3}$ & $\mathbf{0 . 0 0 1}$ & Cat. 4 \\
Coast & $\mathbf{0 . 0 0 0}$ & $\mathbf{0 . 0 0 1}$ & Gulf & 0.504 & 0.807 & - \\
Track & $\mathbf{0 . 0 4 7}$ & $\mathbf{0 . 0 0 7}$ & Over & 0.614 & 0.856 & - \\
Land time & $\mathbf{0 . 0 0 8}$ & 0.078 & 24 h & 0.117 & 0.527 & - \\
Duration & 0.882 & 0.883 & - & 0.247 & 0.307 & - \\
\hline
\end{tabular}

Bold values indicate results that are statistically significant at $\alpha=0.05$

also identified storm intensity as an important factor that influenced decisions to evacuate. Overall, tourists that perceived a high level of risk (rating 4 or 5) and those most likely to evacuate (rating 4 or 5) viewed more scenarios containing Category 4 hurricanes than Category 1 hurricanes. Although only 5\% Pinellas County tourists indicated that they did not know of their risk or likelihood to evacuate, $77 \%$ of these tourists viewed Category 4 scenarios. Again, this finding suggests that tourists need to be better educated on the potential dangers associated with remaining near the coast when a hurricane landfall is expected, particularly when the storm is forecast to have a high intensity.

The results that examined coast of landfall, track location, and time until landfall were statistically significant only for Pinellas County. Since they were surveyed while standing on the Gulf Coast, it is not surprising that more tourists indicated higher ratings when the hurricane was projected to make landfall along the Gulf rather than the Atlantic Coast. Twice as many tourists rated their likelihood to evacuate for a Gulf landfall as a 5 rather than a 4, while ratings for Atlantic landfalls were distributed fairly evenly among all five ratings. A similar result was achieved for the likelihood to evacuate when the centerline of the cone was projected to pass directly over the survey region; nearly twice as many tourists indicated a rating of 5 when compared to any other rating. As all survey locations were located within the cone, where the maximum sustained winds of the approaching storm are expected to occur $60-70 \%$ of the time, altering the position of the centerline should not have produced a difference in ratings that was statistically significant. The fact that a statistically significant difference was found implies that tourists like residents (Broad et al. 2007) may place too much emphasis on the centerline and misinterpret their risk upon viewing the track forecast cone map. When the hurricane was projected to make landfall within $24 \mathrm{~h}$, more (fewer) tourists selected 3 (1) than expected, which accounted for the statistically significant difference between 24 and $48 \mathrm{~h}$ landfall times. Given that evacuation lead times for major urban areas can be 48-72 h (Regnier 2008), it is important to note that tourists may not be as likely to react at these longer lead times. Overall, these results indicate that our second hypothesis was supported and accepted.

\subsection{Effect of tourist attributes}

We are also able to accept our third hypothesis. For six of the 24 tourist attributes, all four chi-square tests produced statistically significant results (Table 6), and these included demographics, trip length, and previous experience with hurricanes. Tourists perceiving the highest levels of risk and most likely to evacuate in both Pinellas and Orange Counties had a trip duration less than 6 days; were not previously affected by a hurricane; did not 
Table 6 Results of chi-square tests to determine which attributes of the tourists had the greatest influence on the perception of risk and likelihood to evacuate for tourists surveyed in Pinellas and Orange Counties

\begin{tabular}{|c|c|c|c|c|c|c|}
\hline & $\begin{array}{l}\text { Pinellas } \\
\text { county risk } \\
\text { perception }\end{array}$ & $\begin{array}{l}\text { Pinellas county } \\
\text { likelihood to } \\
\text { evacuate }\end{array}$ & $\begin{array}{l}\text { Higher/ } \\
\text { lower } \\
\text { rating } \\
\text { group }\end{array}$ & $\begin{array}{l}\text { Orange } \\
\text { county risk } \\
\text { perception }\end{array}$ & $\begin{array}{l}\text { Orange county } \\
\text { likelihood to } \\
\text { evacuate }\end{array}$ & $\begin{array}{l}\text { Higher/ } \\
\text { lower } \\
\text { rating } \\
\text { group }\end{array}$ \\
\hline Reside & 0.000 & 0.003 & $3 / 2 ; 3 / 1$ & 0.000 & 0.000 & $2 / 3 ; 1 / 3$ \\
\hline N Days & 0.002 & 0.002 & $1 / 2 ; 1,4 / 3$ & 0.000 & 0.000 & $1 / 4 ; 2 / 4$ \\
\hline Age & 0.000 & 0.000 & $5 / 1 ; 5 / 2$ & 0.000 & 0.000 & $5 / 3 ; 1 / 4$ \\
\hline Affect P & $\mathbf{0 . 0 3 7}$ & 0.007 & $0 / 1$ & 0.000 & 0.000 & $0 / 1$ \\
\hline Hurricane Possibility & 0.002 & 0.034 & $1 / 0$ & 0.044 & 0.000 & $1 / 0$ \\
\hline Affect $\mathrm{F}$ & 0.000 & 0.024 & $0 / 1$ & 0.048 & 0.042 & $0 / 1$ \\
\hline Child & 0.000 & 0.057 & $1 / 0$ & 0.006 & 0.823 & $1 / 0$ \\
\hline F Visit & 0.035 & 0.174 & $1 / 0$ & 0.053 & 0.000 & $1 / 0$ \\
\hline Gender & 0.231 & 0.091 & $1 / 0$ & 0.000 & 0.002 & $1 / 0$ \\
\hline Info Hotel & 0.064 & 0.000 & $0 / 1$ & 0.866 & 0.000 & $1 / 0$ \\
\hline Q unknown & 0.514 & 0.651 & - & 0.009 & 0.000 & $1 / 0$ \\
\hline Info WC & 0.050 & 0.571 & $1 / 0$ & 0.672 & 0.003 & $1 / 0$ \\
\hline Mode AP & 0.067 & 0.256 & $0 / 1$ & 0.033 & 0.008 & $0 / 1$ \\
\hline Mode RV & 0.192 & 0.000 & $0 / 1$ & 0.430 & 0.499 & - \\
\hline Mode PV & 0.136 & 0.292 & $1 / 0$ & 0.119 & 0.038 & $1 / 0$ \\
\hline
\end{tabular}

Bold values indicate results that are statistically significant at $\alpha=0.05$

have a family member that was previously affected by a hurricane; and had checked for the possibility of a hurricane strike prior to current trip departure. Two of four chi-square tests produced results significant at $\alpha=0.05$ in seven of the remaining variables, which include being on a first visit to the destination, gender, traveling with children, not knowing the knowledge questions, traveling by airplane, and obtaining information from hotel staff or the Weather Channel (Table 6). Below, we provide a detailed discussion of the most important factors as revealed by the chi-square results. It is important to note that our explanations are plausible reasons for the statistical relationships, and future studies should aim to test these more directly with appropriately worded questions in the surveys.

A short trip and/or this trip being the first visit to the destination may lead to an increased perception of risk and likelihood to evacuate as tourists do not have enough time to familiarize themselves with the new environment and the support system in the destination. Previous research has shown that this situation leads to anxiety, which is one consequence of being exposed to potential risks (Dowling and Staelin 1994; Reisinger and Mavondo 2005). On the other hand, tourists who frequent the destination are more familiar with their surroundings, which may reduce their anxiety level. Thus, they where to find information and can appropriately decide what action should be taken in the event of a hurricane. Vogt and Fesenmaier (1998) asserted that tourists averse to risk and uncertainty are more likely to engage in strategies that reduce risk and uncertainty such as searching information extensively during the decision-making process. Their findings help to explain why tourists who checked for the possibility of a hurricane strike before departing on their trip were more likely to evacuate.

Our finding that previous hurricane experience was linked to a lower evacuation likelihood in both regions (Table 6) is interesting particularly in relation to the resident 
population. Lazo et al.(2010) and Lindell et al. (2005) found that prior experience exhibited no effect on the evacuation decisions of residents, and Riad et al. (1999) and Burnside et al. (2007) found that residents evacuating previously were extremely likely to evacuate again. We found that the $25 \%$ of tourists who had been previously affected by a hurricane or typhoon perceived the scenarios that they viewed as less risky and were less likely to evacuate than tourists without this prior experience. In addition, nearly half of the tourists surveyed indicated that their family and/or friends had been affected by a hurricane or typhoon. These tourists were also less likely to evacuate and perceived a lower level of risk when compared to those who did not know someone that had been affected. Our results concur with those from studies of residents conducted by Kusenbach et al. (2010) and Rincon et al. (2001). One possible explanation is that previous hurricanes encountered by tourists were weak or short-lived, or the storms that not pass near enough to their location to cause significant damage. Another possibility is that tourists faced problems during past attempts to evacuate such as crowded or closed airports, making them less willing to evacuate for future hurricanes. The aforesaid possibility is parallel with Johnson and Tversky's (1983) finding that people often use past situations as an anchor in the decision making in the new situation they face and that individual's experience with particular risks could transfer to the individual response to other risks.

An examination of both the location of the tourist's home residence and age also produced statistically significant results for risk perception and evacuation likelihood. However, the groups differed between the two survey counties. International tourists surveyed in Pinellas County indicated the highest risk and were most likely to evacuate, while tourists in Orange County from the USA but outside of Florida perceived the highest risk and those from Florida were most likely to evacuate. One explanation for this result is that international tourists perceive hurricanes to be a threat primarily to coastal locations and may not understand the levels of damage that can also occur inland. Previous hurricane evacuation studies have yielded mixed results when considering age (Baker 1991). Our results indicate that tourists aged 50 and higher provided the highest ratings overall in Pinellas County and for risk perception in Orange County, yet tourists aged 18-29 were most likely to evacuate from Orange County. Some authors report that older populations are less likely to evacuate relative to younger populations due to lower income or inability to travel due to health reasons (Baker 1979; Drabek 1986; Eisenman et al. 1997). However, the tourists we surveyed were capable of travel from both a health and income perspective; this could be one reason why older tourists indicated higher ratings than might be expected. The mixed results obtained for both home residence and age suggest that further research is required to more fully understand the key factors influencing risk perception and evacuation likelihoods of tourists.

Some previous studies have shown that women (Lindell et al. 2005; Riad et al. 1999; Smith and McCarty 2009) and households with children under 18 years of age (Dash and Gladwin 2007; Lindell et al. 2005; Smith and McCarty 2009) are more likely to evacuate, while other studies have not found this to be the case (Baker 1991; Burnside et al. 2007; Lazo et al. 2010). In our study, more men than women were surveyed in Orange County, while the opposite was true in Pinellas County. Women tended to offer higher ratings for both risk perception and evacuation likelihood than men in both regions, however, the chitest results were significant at $\alpha=0.05$ only in Orange County (Table 6). One possible explanation for this outcome may be the presence of children. More children accompanied Orange County tourists that Pinellas County tourists. A chi-square test examining the number of children in each group according to whether the tourist surveyed was male or female produced a $p$ value of 0.0002 . This indicated that more women than expected 
travelled with children, while more men than expected travelled without children. So, it may be due to the presence of children in their travel groups that gender was highly statistically significant only for Orange County. Interestingly, our study shows that the presence of children does not correspond with higher ratings for the likelihood of evacuation, but tourists with children indicated higher ratings of risk perception than expected in both regions (Table 6). One explanation may be that those with children may have a higher perception of risk but do not know where to go or what to do and therefore, they elect to stay in place. However, our uni-variate analysis methods do not allow us to further explore the complicated interactions between factors that may influence the decisions of the tourists, thus future research into this issue is warranted.

Modes of transportation exhibited statistically significant correlations in four of twelve chi-square tests (Table 6). Tourists that flew or rented a vehicle indicated lower ratings than expected as compared to tourists that did not use these modes of transportation. On the other hand, tourists that used their personal vehicle indicated a higher likelihood to evacuate than was expected compared to tourists who did not travel in their own vehicle. Eisenman et al. (1997) found that resident populations without access to modes of transportation under their control were less likely to evacuate. Tourists who rent vehicles and/or rely on airlines for transportation might incur unexpected costs and face long lines when attempting to change their travel plans, which might lead to the decision not to evacuate. These tourists may need to be better educated about their relocation options should a hurricane occur during their trip. Several previous studies have found that traffic congestion is not a major concern for area residents during evacuation (Dow and Cutter 2002; Lindell et al. 2005). Although tourists renting vehicles provided lower ratings, tourists traveling in their own vehicle indicated higher ratings of evacuation likelihoods and perceptions of risk than those that did not travel in their own vehicle. Overall, these results suggest that reliance on transportation not in one's personal control, rather than fears of traffic congestion, could lower the evacuation rates, while the flexibility of reliance on a personal vehicle may enable tourists to evacuate.

\section{Conclusions and future research}

As tourists are a vulnerable population when natural disasters occur, we surveyed tourists visiting the beaches of Pinellas County and inland locations near Orlando, Florida. We collected information on the hurricane-based knowledge and experience of the tourists along with their trip logistics and basic demographics. For the stated preference portion of the survey, each tourist indicated their perception of the risk associated with remaining at their location and likelihood that they would evacuate upon viewing four different hurricane scenarios. Each scenario included a track forecast cone depicting a hurricane expected to make landfall over Florida, and all survey sites were located within the white cone. In addition to seeing information related to the location of landfall, the time until landfall, the centerline of the cone passing either over or to the side of the survey site, information about storm intensity and duration were also provided. Our key results include:

- The ratings for perception of risk did not match precisely those for likelihood to evacuate.

- Coastal tourists indicated a higher likelihood to evacuate than did inland tourists.

- Tourists perceived a higher level of risk and were more likely to evacuate for a Category 4 than for a Category 1 hurricane, regardless of their location. 
- Tourists located in Pinellas County perceived the highest level of risk and were most likely to evacuate for a hurricane making landfall along the Gulf Coast with the centerline passing over their location within $24 \mathrm{~h}$.

- Tourists who perceived the highest levels of risk and most likely to evacuate in both Pinellas and Orange Counties were not previously affected by a hurricane; did not have a family member that was previously affected by a hurricane; had a trip duration less than 6 days; and had checked for the possibility of a hurricane strike before departing on their trip.

- Tourists who flew or rented a vehicle indicated that they were less likely to evacuate, while those who utilized their own vehicles indicated a higher risk perception (Pinellas County) or likelihood to evacuate (Orange County).

- Tourists with children indicated a higher perception of risk, but the likelihood of evacuation did not differ significantly for those who travelled with or without children.

While this empirical study represents a first step toward understanding the risk perceptions and evacuation decisions of tourists, it is important to emphasize that the actual behaviors of tourists when hurricanes affect the area may differ from their responses on the SP surveys. Although limited in sample size, number of potential scenarios, and geographic locations, several key insights were obtained. Our results suggest that most tourists have some knowledge about hurricanes but may be misinterpreting the track forecast cone. As this misinterpretation means that they may not be aware of the true risk that they face if they remain in a coastal location; tourists need to be better educated about these graphics. Our findings that tourists may be misinterpreting the track forecast cone and that tourists with previous hurricane experience are less likely to evacuate are similar to those reported by studies surveying residents (Broad et al. 2007; Kusenbach et al. 2010; Rincon et al. 2001). This suggests that similar surveys should be administered to residents as well as additional tourists to more accurately compare the responses from these two populations.

Future surveys should also include questions that more specifically address how tourists and residents interpret the track forecast cone and the five hurricane conditions. Our results indicate that tourists would most often consult local television to obtain hurricane-related information, but many would check multiple sources including the Weather Channel. Future surveys could also be conducted at a time when a hurricane is near Florida to determine whether the increased media coverage might allow for a more accurate interpretation of the information by tourists, which could then lead to a more realistic perception of risk and higher likelihood to evacuate coastal locations. Landfall times that are more consistent with the lead times needed to evacuate the region could also be utilized in future studies.

Acknowledgments We thank the Eric Friedheim Foundation for their financial contribution that allowed us to conduct this study. We also thank the team of student assistants who helped to administer the surveys and two anonymous reviewers for their helpful comments.

\section{References}

Arlikatti S, Lindell MK, Prater CS, Zhang Y (2006) Risk area accuracy and hurricane evacuation expectations of coastal residents. Environ Behav 38:226-247

Baker EJ (1979) Predicting response to hurricane warnings: a reanalysis of data from four studies. Mass Emerg 4:9-24

Baker EJ (1991) Hurricane evacuation behavior. Int J Mass Emerg Dis 9:287-310

Broad K, Leiserowitz A, Weinkle J, Steketee M (2007) Misinterpretations of the "Cone of Uncertainty" in Florida during the 2004 hurricane season. Bull Am Meteorol Soc 88:651-667. doi:10.1175/ bams-88-5-651

Burby RJ, Wagner F (1996) Protecting tourists from death and injury in coastal storms. Disasters 20:49-60 
Burnside R, Miller DS, Rivera JD (2007) The impact of information and risk perception on the hurricane evacuation decision-making of greater New Orleans residents. Sociol Spect 27:727-740. doi: $10.1080 / 02732170701534226$

Cutter SL, Finch C (2008) Temporal and spatial changes in social vulnerability to natural hazards. Proc Nat Acad Sci USA 105:2301-2306. doi:10.1073/pnas.0710375105

Cutter SL, Smith MM (2009) Fleeing from the hurricane's wrath: evacuation and the two Americas. Environment 51:26-36

Daniels RJ, Loggins GM (2007) Conceptualizing continuous coverage: a strategic model for wall-to-wall local television weather broadcasts. J Appl Comm Res 35:48-66

Dash N, Gladwin H (2007) Evacuation decision making and behavioral responses: individual and household. Nat Hazards Rev 8:69-77

Dow K, Cutter SL (2002) Emerging hurricane evacuation issues: Hurricane Floyd and South Carolina. Nat Hazards Rev 3:12-18

Dowling G, Staelin R (1994) A model of perceived risk and intended risk-handling activity. J Consumer Res 21:119-135

Drabek TE (1986) Human system responses to disaster. Springer, New York

Drabek TE (1991) Anticipating organizational evacuations: disaster planning by managers of tourist-oriented private firms. Int J Mass Emerg Dis 9:219-245

Drabek TE (1993) Variations in disaster evacuation behavior: public responses versus private sector executive decision-making processes. Disasters 16:104-118

Drabek TE (1994) Disaster evacuation and the tourist industry. In: Environment and behavior monograph no. 57. Natural Hazards Research and Application Information Center, Boulder, CO. p 282

Drabek TE (1996) Disaster evacuation behavior: tourists and other transients. In: Environment and behavior monograph no. 58. Natural Hazards Research and Application Information Center, Boulder, CO. p 354

Eisenman DP, Cordasco KM, Asch S, Golden JF, Glik D (1997) Disaster planning and risk communication with vulnerable communities: lessons from Hurricane Katrina. Amer J Public Health 97:109-115

Elsberry RL, Lambert TDB, Boothe MA (2007) Accuracy of Atlantic and eastern North Pacific tropical cyclone intensity forecast guidance. Weather Forecast 22:747-762. doi:10.1175/waf1015.1

Elsner JB, Niu XF, Jagger TH (2004) Detecting shifts in hurricane rates using a Markov chain Monte Carlo approach. J Clim 17:2652-2666

Floyd MF, Gibson H, Pennington-Gray L, Thapa B (2004) The effect of risk perceptions on intentions to travel in the aftermath of September 11, 2001. J Travel Tour Market 15:19-38

Fu H (2004) Development of dynamic travel demand model for hurricane evacuation. Dissertation, Louisiana State University

Hess S, Adler T, Polak JW (2006) Modeling airport and airline choice behavior with the use of stated preference survey data. Transport Res Part E 43:221-225

Huan TC, Beaman J, Shelby L (2004) No-escape natural disaster: mitigating impacts on tourism. Ann Tour Res 31:255-273

Johnson EJ, Tversky A (1983) Affect, generalization, and the perception of risk. J Personal Soc 45:20-31

Kang JE, Lindell MK, Prater CS (2007) Hurricane evacuation expectations and actual behavior in Hurricane Lili. J Appl Soc Psych 37:887-903

Kimball SK, Mulekar MS (2004) A 15 year climatology of North Atlantic tropical cyclones. Part I Size Parameters 17:3555-3575

Kozak M, Crotts J, Law R (2007) The impact of the perception of risk on international travelers. Int J Tour Res 9:233-242

Kroes EP, Sheldon RJ (1988) Stated preference methods. J Trans Econ Policy 22:11-25

Kusenbach M, Simms JL, Tobin GA (2010) Disaster vulnerability and evacuation readiness: coastal mobile home residents in Florida. Nat Hazards 52:79-95. doi:10.1007/s11069-009-9358-3

Lau J, Xilin Y, Tsui HY, Pang E (2004) SARS related preventive and risk behaviours practised by Hong Kong-mainland China cross border travellers during the outbreak of the SARS epidemic in Hong Kong. J Epidemiol Commun Health 58:988-996

Lazo JK, Waldman DM, Morrow BH, Thacher JA (2010) Household evacuation decision making and the benefits of improved hurricane forecasting: developing a framework for assessment. Weather Forecast 25:207-219

Lee WC, Bell MM (2007) Rapid intensification, eyewall contraction, and breakdown of Hurricane Charley (2004) near landfall. Geophys Res Lett 34:5. doi:10.1029/2006GL027889

Lepp A, Gibson H (2008) Sensation seeking and tourism: tourist role, perception of risk and destination choice. Tour Manag 29:740-750

Lindell MK, Perry RW (2004) Communicating environmental risk in multiethnic communities. Sage, Thousand Oaks, CA 
Lindell MK, Prater CS (2007) A hurricane evacuation management decision support system (EMDSS). Nat Hazards 40:627-634. doi:10.1007/s11069-006-9013-1

Lindell MK, Lu JC, Prater CS (2005) Household decision making and evacuation in response to Hurricane Lili. Nat Hazards Rev 6:171-179

Matyas CJ (2010) Associations between the size of hurricane rain fields at landfall and their surrounding environments. Meteorol Atmos Phys 106:135-148. doi:10.1007/s00703-009-0056-1

NHC (2011) Definition of the NHC track forecast cone. http://www.nhc.noaa.gov/aboutcone.shtml. Accessed 21 Mar 2011

Park K, Reisinger Y (2010) Differences in the perceived influence of natural disasters and travel risk on international travel. Tour Geogr 12:1-24

Phillips BD, Morrow BH (2007) Social science research needs: focus on vulnerable populations, forecasting, and warnings. Nat Hazards Rev 8:61-68

Rappaport EN (2000) Loss of life in the United States associated with recent Atlantic tropical cyclones. Bull Amer Meteorol Soc 81:2065-2073

Rappaport EN, Franklin JL, Avila LA, Baig SR, Beven JL, Blake ES, Burr CA, Jiing JG, Juckins CA, Knabb RD, Landsea CW, Mainelli M, Mayfield M, McAdie CJ, Pasch RJ, Sisko C, Stewart SR, Tribble AN (2009) Advances and challenges at the national Hurricane center. Weather Forecast 24:395-419. doi: $10.1175 / 2008$ waf2222128.1

Regnier E (2008) Public evacuation decisions and hurricane track uncertainty. Manage Sci 54:16-28. doi: 10.1287/mnsc. 1070.0764

Reisinger Y, Mavondo F (2005) Travel anxiety and intentions to travel internationally: implications of travel risk perception. J Travel Res 43:212-225

Riad J, Norris F, Ruback R (1999) Predicting evacuation in two major disasters: risk perception, social influence, and access to resources. J Appl Soc Psych 29:918-934

Rincon E, Linares MYR, Greenberg B (2001) Effect of previous experience of a hurricane on preparedness for future hurricanes. Amer J Emerg Med 19:276-279

Senkbeil JC, Brommer DM, Dixon PG, Brown ME, Sherman-Morris K (2010) The perceived landfall location of evacuees from Hurricane Gustav. Nat Hazard 54:141-158. doi:10.1007/s11069-009-9457-1

Sheets RC (1990) The National Hurricane Center-past, present, and future. Weather Forecast 5:185-232

Simpson RH, Saffir H (1974) The hurricane disaster-potential scale. Weatherwise 27:169-186

Smith SK, McCarty C (2009) Fleeing the storm(s): an examination of evacuation behavior during Florida's 2004 hurricane season. Demography 46:127-145

Sonmez S, Graefe AR (1998) Determining future travel behavior from past travel experience and perceptions of risk and safety. J Travel Res 37:171-177

Thapa B, Holland S, Absher J (2008) Perceived risk, attitude, knowledge and reactionary behaviors towards wildfires among Florida tourists. In: Chavez D, Absher J, Winter P (eds) Fire social science research from the pacific southwest research station. Gen. Tech. Rep. PSWGTR-209. USFS: Pacific Southwest Research Station, Albany, CA, pp 87-101

Uriely N, Maoz D, Reichel A (2007) Rationalising terror-related risks: the case of Israeli tourists in Sinai. Int J Tour Res 9:1-8

Visit Florida (2010) 2009 Estimates of Florida visitors. Research department, Visit Florida, Tallahassee, FL

Vogt CA, Fesenmaier DR (1998) Expanding the functional information search model. Ann Tour Res 25:551-578

Wardman M (1988) A comparison of revealed preference and stated preference models of travel behavior. J Trans Econ Policy 22:71-91

West DM, Orr M (2007) Race, gender, and communications in natural disasters. Policy Stu J 35:569-586

Whitehead JC (2003) One million dollars per mile? The opportunity costs of Hurricane evacuation. Ocean Coast Manag 46:1069-1083. doi:10.1016/j.ocecoaman.2003.11.001

Whitehead JC (2005) Environmental risk and averting behavior: Predictive validity of jointly estimated revealed and stated behavior data. Env Res Econ 32:301-316

Whitehead JC, Edwards B, Van Willigen M, Maiolo JR, Wilson K, Smith KT (2000) Heading for higher ground: factors affecting real and hypothetical hurricane evacuation behavior. Environ Hazard 2:133-142

Wilks DS (1995) Statistical methods in the atmospheric sciences. Academic Press, San Diego, CA

World Tourism Organization (1998) Handbook on natural disaster reduction in tourist areas. World Meteorological Organization and World Tourism Organization, Madrid

Zhang FQ, Morss RE, Sippel JA, Beckman TK, Clements NC, Hampshire NL, Harvey JN, Hernandez JM, Morgan ZC, Mosier RM, Wang S, Winkley SD (2007) An in-person survey investigating public perceptions of and responses to hurricane Rita forecasts along the Texas Coast. Weather Forecast 22:1177-1190. doi:10.1175/2007waf2006118.1 